\title{
Correction to: Printed and hybrid integrated electronics using bio-based and recycled materials-increasing sustainability with greener materials and technologies
}

\author{
Marja K. Välimäki ${ }^{1}$ • Laura I. Sokka ${ }^{2}$ • Heidi B. Peltola ${ }^{3} \cdot$ Sami S. Ihme $^{1} \cdot$ Teijo M. J. Rokkonen $^{3} \cdot$ Timo J. Kurkela $^{1}$ • \\ Jyrki T. Ollila ${ }^{1} \cdot$ Arttu T. Korhonen ${ }^{1} \cdot$ Jukka T. Hast $^{1}$ \\ Published online: 28 October 2020 \\ (C) Springer-Verlag London Ltd., part of Springer Nature 2020
}

Correction to: The International Journal of Advanced Manufacturing Technology (2020) 111:325-339 https://doi.org/10.1007/s00170-020-06029-8

The funding note is missing in the paper. The funding note to add is the following: Open access funding provided by Technical Research Centre of Finland (VTT).

The original article has been corrected.

Publisher's note Springer Nature remains neutral with regard to jurisdictional claims in published maps and institutional affiliations.

The online version of the original article can be found at https://doi.org/ 10.1007/s00170-020-06029-8

Marja K. Välimäki

Marja.Valimaki@vtt.fi

1 VTT Technical Research Centre of Finland, Kaitoväylä 1,

P.O. Box 1100, FI-90571 Oulu, Finland

2 VTT Technical Research Centre of Finland, Vuorimiehentie 3,

P.O. Box 1000, FI-02150 Espoo, Finland

3 VTT Technical Research Centre of Finland, Visiokatu 4,

P.O. Box PL 1300, FI-33720 Tampere, Finland 